\title{
INCORPORAÇÃO DE DIÓXIDO DE TITÂNIO EM ZEÓLITAS PARA EMPREGO EM FOTOCATÁLISE HETEROGÊNEA
}

\author{
Jean C. Merg, Franciele Rossett, Fábio G. Penha e Sibele B. C. Pergher* \\ Departamento de Química, Universidade Regional Integrada do Alto Uruguai e das Missões, Campus Erechim, Av. Sete de \\ Setembro, 1621, 99700-000 Erechim - RS, Brasil \\ Diego I. Petkowicz e João H. Z. dos Santos \\ Instituto de Química, Universidade Federal do Rio Grande do Sul, Av. Bento Gonçalves, 9500, 91501-970 Porto Alegre - RS, Brasil
}

Recebido em 4/11/09; aceito em 22/3/10; publicado na web em 20/7/10

\begin{abstract}
TITANIUM OXIDE INCORPORATION ON ZEOLITES FOR HETEROGENEOUS PHOTOCATALISIS. This work proposes the study of heterogeneous photocatalysis using $\mathrm{TiO}_{2}$ impregnated in zeolites beta, ZSM-5, mordenite, $\mathrm{NaX}_{\mathrm{b}}, \mathrm{NaX}_{\mathrm{p}}$ and $\mathrm{NaY}$ for the decomposition of methylene blue. The catalysts were characterized by XRD, IR, textural analyses by $\mathrm{N}_{2}$ adsorption, SEM, DRS and the reaction of decomposition was monitored by UV visible. The results indicated that didn't have structural changes in the catalysts after Ti impregnations, only in the case of $\mathrm{NaY}$ and $\mathrm{NaX}$ zeolites. The better photocatalyst to metylene blue decomposition was beta/ Ti zeolite due had one structure more accessible (with bigger porous) helping in $\mathrm{TiO}_{2}$ dispersion and catalytic active.
\end{abstract}

Keywords: titanium oxide; zeolites; photocatalysis.

\section{INTRODUÇÃO}

A contaminação do meio ambiente tem sido apontada como um dos maiores problemas da sociedade moderna. Como resultado de uma crescente conscientização deste problema, novas normas e legislações cada vez mais restritas têm sido adotadas a fim de minimizar o impacto ambiental. ${ }^{1}$

A presença dos denominados poluentes prioritários tem sido objeto de intensa preocupação e vigilância nas últimas três décadas devido aos potenciais riscos à saúde humana, em função de sua toxidade, efeitos carcinogênicos e mutagênicos, além de sua persistência no meio ambiente. Contudo, numerosos outros produtos químicos vêm sendo continuamente lançados no meio ambiente a partir de variadas fontes, tais como indústria, agricultura ou esgoto doméstico. Esses poluentes, denominados contaminantes emergentes abrangem fármacos, cosméticos, surfactantes, aditivos para a gasolina, compostos orgânicos fluorados, corantes, entre outros. Especificamente, no caso de corantes, esses representam uma série de risco para o meio aquático, à medida que alteram a difusão da luz solar nesse meio afetando, por sua vez, o ecossistema. ${ }^{2}$

O processo fotocatalítico heterogêneo é uma tecnologia que vem ganhando importância recentemente no tratamento de contaminantes. O processo é baseado na irradiação (fonte de luz ultravioleta) de semicondutores inorgânicos, mais comumente o dióxido de titânio $\left(\mathrm{TiO}_{2}\right)$. Este é empregado por apresentar baixo custo e características importantes, como fotoestabilidade e baixa toxidade. A grande vantagem do processo é que durante o tratamento os poluentes são eliminados e não simplesmente transferidos de uma fase para outra, como ocorre em muitos processos convencionais. ${ }^{3}$ Apesar de ser comprovado o potencial de degradação desses processos utilizando luz solar, seu emprego em escala industrial ainda exige maiores estudos para torná-los competitivos em comparação aos processos convencionais estabelecidos no mercado. ${ }^{4}$

Apesar da elevada atividade catalítica apontada por catalisadores à base de $\mathrm{TiO}_{2}$, sua reutilização como catalisador fica muito comprometida haja vista seu tamanho de partícula extremamente pequeno,

*e-mail: sibelepergher@gmail.com o que dificulta processos de filtração. A imobilização de $\mathrm{TiO}_{2}$ sobre suportes inorgânicos, dotados de partículas com dimensões micrométricas, vem sendo apontada como uma estratégia para superar esse inconveniente. Além disso, a própria superfície do suporte deve desempenhar um papel coadjuvante, favorecendo processos de adsorção de moléculas para posterior degradação. Dentre os diversos suportes investigados na literatura, zeólitas ocupam um papel de destaque. ${ }^{5-10}$

As zeólitas são materiais acessíveis, de baixo custo e excelentes trocadores iônicos, razão pela qual são empregadas para a adsorção de contaminantes. A sua capacidade de adsorção é resultante da alta área superficial e da carga líquida negativa nos canais de sua estrutura, que atraem cátions. ${ }^{11}$ Cabe ressaltar que o desenvolvimento de fotocatalisadores suportados não confere apenas vantagens a esses sistemas. A exemplo do que ocorre com catalisadores heterogêneos em geral, a imobilização sobre um suporte traz vantagens referentes ao processo de separação (as etapas de filtração são extremamente eficientes à recuperação do catalisador para reutilização), ao espaçamento das espécies sobre uma superfície (evitando processos de sinterização, o que pode acarretar perda na atividade catalítica), além de estabilidade mecânica e térmica aos materiais resultados. Contudo, a heterogeneização acarreta também desvantagens: a superfície do suporte desempenha o papel de um ligante volumoso, dificultando o acesso do substrato aos centros catalíticos. Além disso, processos de heteogeneização caracterizam-se pelo risco de dificuldade de reprodutibilidade, tendo em vista que defeitos inerentes à superfície do suporte podem variar de lote para lote. Além disso, o controle da reação de heterogeneização entre as espécies de interesse e a superfície do suporte é muito mais dificilmente controlada. No entanto, tendo em vista que a etapa de separação do catalisador (para sua reutilização) representa uma etapa determinada no delineamento de um processo industrial, a heterogeneização, mesmo implicando em certas desvantagens, acaba resultando em uma abordagem atrativa no desenvolvimento de fotocalisadores.

O presente trabalho teve por objetivo estudar a fotocatálise heterogênea, impregnando dióxido de titânio $\left(\mathrm{TiO}_{2}\right)$ em diferentes estruturas zeolíticas, irradiado por luz UV-visível, utilizando azul de metileno como molécula sonda. 


\section{PARTE EXPERIMENTAL}

\section{Materiais}

Para a preparação dos fotocatalisadores foram utilizadas 6 zeólitas comerciais $\left(\mathrm{NaX}_{\mathrm{b}}, \mathrm{NaX}, \mathrm{NaY}\right.$, Beta, ZSM-5 e Mordenita). Para o preparo dos catalisadores foram usados tetracloreto de titânio (IV) (Merck) e hexano (Merck). O padrão P-25 (Degussa) foi usado sem qualquer tratamento adicional. Este padrão se apresenta principalmente na forma de anatase ( $80 \%$ de anatase e $20 \%$ de rutilo em peso), possuindo área superficial BET de $50 \mathrm{~m}^{2} / \mathrm{g}$ e tamanho de partícula de aproximadamente $20 \mathrm{~nm}$. Como modelo de poluente orgânico foi utilizado azul de metileno (Basic blue 9 - Sigma-Aldrich). As soluções do corante foram preparadas usando-se água deionizada, sem nenhum tratamento prévio.

\section{Preparo dos fotocatalisadores}

As amostras das zeólitas foram usadas conforme recebidas, sem submetê-las a nenhum tratamento. O catalisador suportado de titânio foi preparado por impregnação do $\mathrm{TiCl}_{4}$ (em hexano) nas zeólitas. Em uma preparação típica, 1,0 g de zeólita foi colocado com uma solução de $\mathrm{TiCl}_{4}$ (correspondente a $10 \%$ em peso Ti/zeólita), sob atmosfera inerte, sob agitação por $1 \mathrm{~h}$ a $100{ }^{\circ} \mathrm{C}$. Após, o solvente foi evaporado, o sólido foi seco a $110{ }^{\circ} \mathrm{C}$ e calcinado a $450{ }^{\circ} \mathrm{C}$ por $4 \mathrm{~h}$. Os materiais foram denominados conforme o tipo de zeólita usada: $\mathrm{NaX}$ na forma de esferas descrito simplesmente aqui como $\mathrm{NaX}_{\mathrm{b}}$, $\mathrm{NaX}$ na forma de pó descrito simplesmente como $\mathrm{NaX}$, NaY, Beta, ZSM-5 e Mordenita; e para os suportes catalíticos adicionou-se Ti na nomenclatura, por exemplo, descrito como NaY/Ti.

\section{Reações fotocatalíticas}

Os fotocatalisadores resultantes foram avaliados na fotodecomposição do azul de metileno por irradiação UV, usando-se um filamento de uma lâmpada de vapor de $\mathrm{Hg} 250 \mathrm{~W}\left(\lambda_{\max }=365 \mathrm{~nm}\right)$. As reações de fotodecomposição foram realizadas em um reator de quartzo, equipado com um dedo frio para manter a temperatura constante e evitar o efeito do aquecimento devido à radiação da lâmpada, sob agitação constante assegurada por um agitador magnético, no intuito de deixar o catalisador em suspensão. O filamento (cerca de $10 \mathrm{~cm}$ ) foi inserido no dedo frio, a uma altura suficiente de forma a irradiar totalmente o volume de solução empregado. Em uma reação típica, $50 \mathrm{mg}$ de catalisador e $150 \mathrm{~mL}$ de solução do corante $\left(30 \mathrm{mg} . \mathrm{L}^{-1}\right)$ foram agitadas e irradiadas por $1 \mathrm{~h}$. Alíquotas foram coletadas em diferentes tempos de irradiação (5, 10, 20, 30 e 60 min). Após, os frascos foram centrifugados a $3000 \mathrm{rpm}$ por $3 \mathrm{~min}$ para a decantação do catalisador. As leituras de absorbância foram realizadas em um espectrofotômetro de UV-Visível, da marca Shimadzu, modelo UV160A, no comprimento de onda de $665 \mathrm{~nm}$.

Os materiais preparados bem como os materiais de partida foram caracterizados por diversas técnicas complementares, tais como, difração de raios-X (DRX), análise textural por adsorção de $\mathrm{N}_{2}$, espectroscopia no infravermelho (IV), microscopia eletrônica de varredura (MEV) e espectrofotometria UV-Visível.

\section{RESULTADOS E DISCUSSÃO}

A seguir serão apresentados os resultados da caracterização dos sólidos preparados a partir de diferentes zeólitas com impregnação de $10 \%$ de Ti. Conforme estudos realizados anteriormente por nosso grupo de trabalho, ${ }^{12}$ ficou claramente demonstrado a partir da caracterização por sonda eletrônica (SEM-EDX) e espectroscopia fotoeletrônica de
raios-X (XPS) que a imobilização de Ti capaz de gerar uma distribuição uniforme no suporte zeolítico é aquela correspondente a 10\% de Ti/zeólita. Valores inferiores produzem sistemas menos ativos e mais passíveis de envenenamento, enquanto valores superiores acarretam a formação de agregados de $\mathrm{TiO}_{2}$ sem interação com o suporte e inativos para as reações de fotodecomposição. Por essa razão, no presente estudo, os catalisadores desenvolvidos foram todos preparados por impregnação de $\mathrm{TiCl}_{4}$, de forma a gerar sistemas com $10 \%$ de Ti/zeólita.

\section{Análise de difração de raios-X}

As Figuras 1 e 2 apresentam os difratogramas de raios-X das amostras antes (Figura 1) e depois (Figura 2) da incorporação de titânio. Observa-se que as zeólitas mordenita, beta e ZSM-5 mantiveram a estrutura zeolítica após a incorporação de $\mathrm{TiO}_{2}$; entretanto, as zeólitas $\mathrm{NaX}$ e $\mathrm{NaY}$ não mantiveram suas estruturas. Isto ocorre provavelmente porque estes materiais possuem uma relação $\mathrm{Si} / \mathrm{Al}$ menor, quer dizer, possuem um teor maior de Al. A impregnação de Ti ocorre via $\mathrm{TiCl}_{4}$ e sabe-se que o $\mathrm{Cl}^{-}$residual na estrutura zeolítica em condições de calcinação (elevadas temperaturas) reage com o Al ocasionando desaluminação e, consequentemente, perda estrutural. Como mostrado na Figura 2, as características dos picos de titânio no DRX foram preponderantemente atribuídas na fase de anatase $2 \theta=25,4,48,3$ e $54,9^{\circ}$, representados pela letra A.

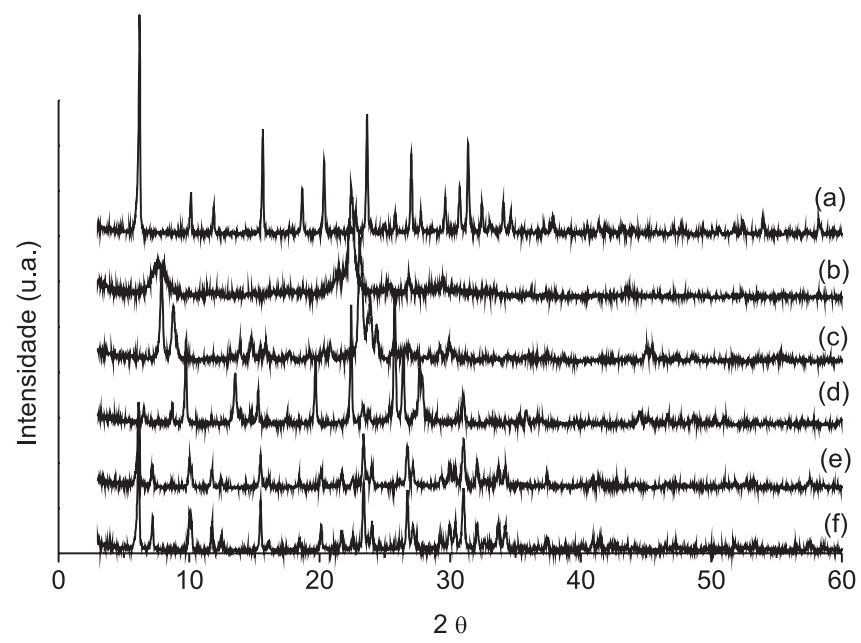

Figura 1. Difratogramas de raios-X das zeólitas comerciais: (a) NaY, (b) Beta, (c) ZSM-5, (d) Mordenita, (e) NaX, (f) NaX

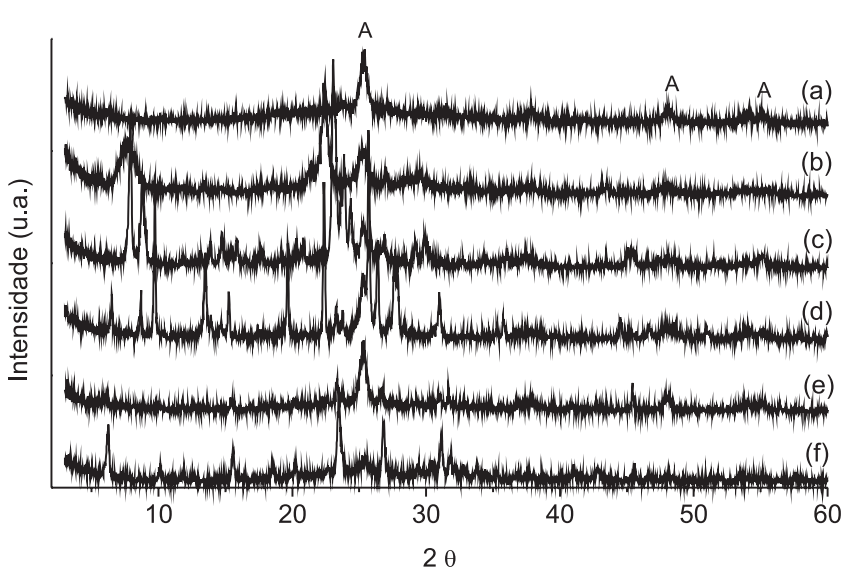

Figura 2. Difratogramas de raios- $X$ das zeólitas comerciais com impregnação de titânio: (a) NaY/Ti, (b) Beta/Ti, (c) ZSM-5/Ti, (d) Mordenita/Ti, (e) NaX/' $\mathrm{Ti}$, (f) $\mathrm{NaX} / \mathrm{Ti}$ 


\section{Análise textural dos materiais (método BET)}

A área superficial específica dos materiais obtidos pelo método BET está apresentada na Tabela 1, onde se observam áreas elevadas típicas de materiais zeolíticos.

Tabela 1. Análise textural das amostras de zeólitas

\begin{tabular}{lcccc}
\hline Amostras & $\begin{array}{c}\text { Área superficial } \\
\left(\mathrm{m}^{2} / \mathrm{g}\right) \text { zeólita } \\
\text { natural }\end{array}$ & $\begin{array}{c}\text { Área superficial } \\
\left(\mathrm{m}^{2} / \mathrm{g}\right) \\
\text { impregnação de } \mathrm{Ti} \text { com }\end{array}$ & $\begin{array}{c}\text { Tamanho } \\
\text { de poro } \\
(\AA)\end{array}$ & $\mathrm{Si} / \mathrm{Al}$ \\
\hline Beta & 327 & 576 & 7,6 & 12,5 \\
ZSM-5 & 391 & 317 & $5,4 \times 5,6$ & 25,0 \\
Mordenita & 398 & 444 & $5,9 \times 7,1$ & 7,5 \\
NaXb & 401 & 242 & 7,8 & 1,5 \\
NaXp & 432 & 408 & 7,8 & 1,5 \\
NaY & 639 & 26 & 7,8 & 2,7 \\
\hline
\end{tabular}

A incorporação de titânio pode ocasionar uma obstrução dos poros zeolíticos diminuindo a acessibilidade e, portanto, a área superficial. No caso da zeólita $\mathrm{NaY}$, a área superficial diminuiu significativamente de 639 para 26,65 m²/g, indicando, como demonstrado na difração de raios $\mathrm{X}$, a destruição da estrutura.

Em poucos casos ocorre um aumento da área superficial com a incorporação de titânio, como na zeólita mordenita. Esse aumento de área pode ser devido a uma liberação dos poros com o processo de calcinação, pelos resquícios de template original de síntese, descartando assim a possibilidade que o aumento da área seja contribuição do $\mathrm{TiO}_{2}$.

\section{Espectroscopia no infravermelho (IV)}

Embora cada estrutura zeolítica apresente um espectro típico, encontram-se características espectrais comuns entre as zeólitas e silicatos, contendo o mesmo tipo de subunidades estruturais, tais como anéis duplos, grupamentos poliédricos de tetraedros e cavidades e abertura de poro. As bandas tornam-se referência para a comprovação da formação de estruturas constituídas, podendo-se citar as bandas em $570 \mathrm{~cm}^{-1}$, características de anéis D6R na estrutura FAU, em 550 $\mathrm{cm}^{-1}$ para os anéis de 5 membros (MFI) e em 550 e $580 \mathrm{~cm}^{-1}$ para os anéis de 5 membros mais $1 \mathrm{TO}_{4}$ (MOR) e em $612 \mathrm{~cm}^{-1} .^{13}$

A Figura 3 mostra o espectro no IV da zeólita Beta e Beta/Ti, no qual se pode perceber que a incorporação de titânio nas zeólitas não modificou os espectros característicos de cada zeólita, concluindose que não houve modificação estrutural nem desaluminização significativa da rede da zeólita devido à modificação com titânio. A partir dos espectros no IV das outras zeólitas chega-se à mesma conclusão. Na Figura 3, após a impregnação do $\mathrm{TiO}_{2}$ é observada

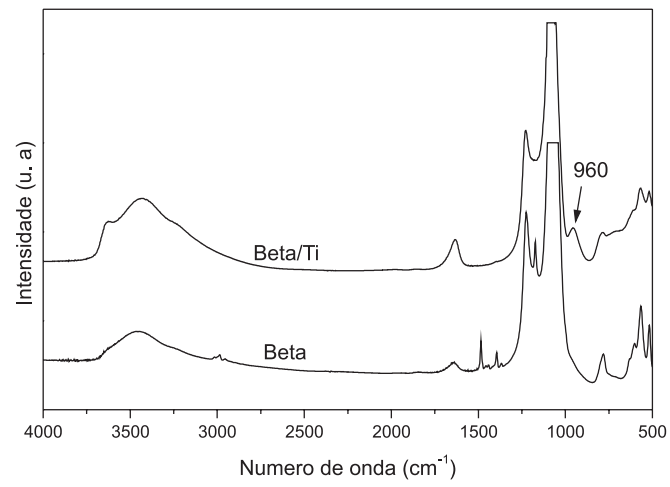

Figura 3. Espectro molecular no IV das amostras zeólita Beta e Beta/Ti a presença uma nova banda em $960 \mathrm{~cm}^{-1}$, que é atribuída ao estiramento vibracional antissimétrico das ligações Ti-O-Si, indicando assim a interação entre o suporte (zeólita) e o catalisador $\left(\mathrm{TiO}_{2}\right){ }^{12}$

\section{Microscopia eletrônica de varredura (MEV)}

As micrografias da zeólita Beta e Beta/Ti estão apresentadas na Figura 4. Pode-se observar que a morfologia dos cristais zeolíticos não foi modificada ao se comparar antes e após a impregnação com Ti. Também se observam aglomerados na morfologia das superfícies das zeólitas, devido ao $\mathrm{TiO}_{2}$.

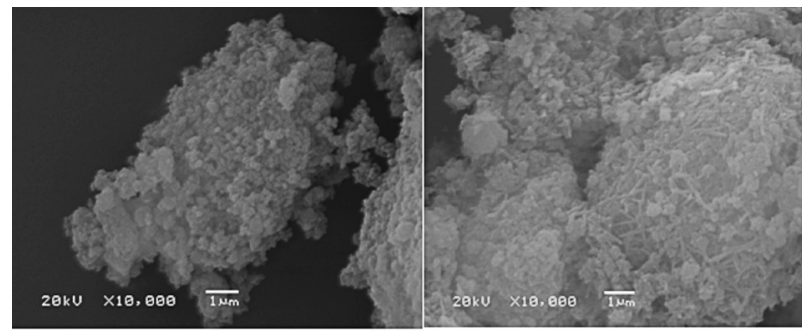

(a)

(b)

Figura 4. Micrografias das zeólitas: (a) Beta, (b) Beta/Ti

\section{Espectroscopia molecular no UV-vis por refletância difusa}

A Figura 5 apresenta os espectros moleculares no UV-vis em modo de refletância difusa dos catalisadores suportados. De acordo com esta figura, a absorção das espécies de titânia geradas in situ é alterada com a variação do suporte. $\mathrm{O}$ espectro é caracterizado por uma larga banda centrada em $350 \mathrm{~nm}$ e atribuída à transferência de elétrons do $\mathrm{O}_{2 \mathrm{p}}$ para $\mathrm{Ti}_{3 \mathrm{~d}}$, correspondendo à banda de valência para a banda de condução de acordo com a estrutura da banda de energia do $\mathrm{TiO}_{2}$. Portanto, a determinação da banda lacuna em espectros de UV-Vis é um método alternativo para se estudar a modificação das propriedades eletrônicas do $\mathrm{TiO}_{2}$.

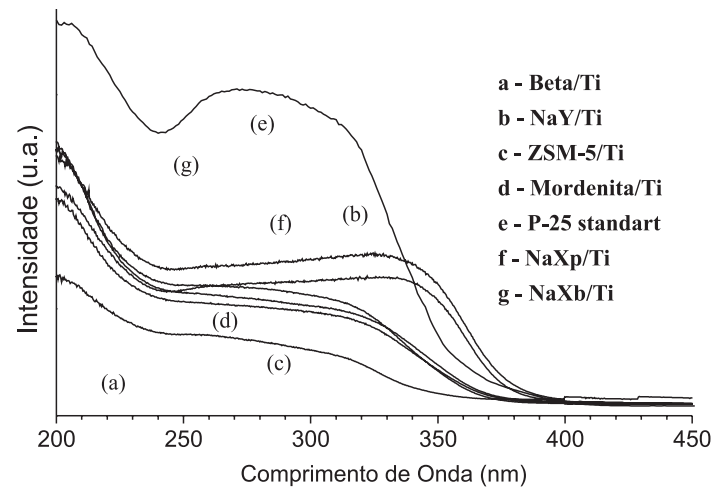

Figura 5. Espectro de reflectância difusa das zeólitas suportadas com titânio

A determinação da energia de lacuna (Eg), definida como gap de energia, foi calculada usando-se o espectro de reflectância UV-vis, de acordo com a literatura. ${ }^{14}$ Os resultados apresentados na Tabela 2 indicam que não houve uma variação significativa nos gaps de energias. Desta maneira, espera-se um comportamento semelhante nas fotodecomposições, exceto para a amostra Beta/Ti, que apresentou um gap de energia de $3,43 \mathrm{eV}$.

\section{Reações fotocatalíticas}

Os testes experimentais foram realizados com as diferentes zeó- 
Tabela 2. Valores do gap de energia e da decomposição do azul de metileno, para os fotocatalisadores obtidos

\begin{tabular}{lcc}
\hline Amostras & Decomposição $(\%)$ & Band Gap $(\mathrm{eV})$ \\
\hline $\mathrm{P}-25$ & 93 & 3,22 \\
$\mathrm{NaXb}$ & 15 & 3,23 \\
$\mathrm{NaXp}$ & 30 & 3,24 \\
$\mathrm{NaY}$ & 55 & 3,34 \\
Mordenita & 30 & 3,29 \\
ZSM-5 & 35 & 3,29 \\
Beta & 97 & 3,43 \\
\hline
\end{tabular}

litas incorporadas com titânio, realizando-se ensaios com irradiação. A Figura 6 apresenta o estudado da reação na ausência de $\mathrm{TiO}_{2}$, onde é observada a baixa eficiência (aproximadamente 20\%) na decomposição do azul de metileno na ausência de um fotocatalisador.

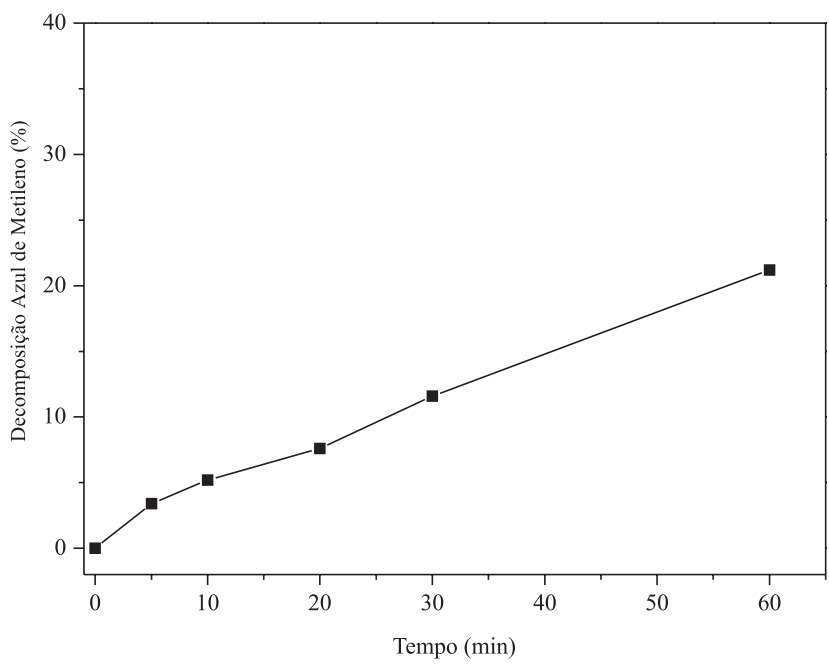

Figura 6. Monitoramento da decomposição do azul de metileno na ausência de fotocatalisadores

A Figura 7 apresenta os resultados da decomposição do azul de metileno empregando-se as zeólitas e um catalisador $\mathrm{TiO}_{2}$ comercial (P-25). No caso das zeólitas $\mathrm{NaX}_{\mathrm{p}}$, mordenita, NaY, $\mathrm{NaX}_{\mathrm{b}}$ e ZSM-5 observam-se atividades similares e menores que o catalisador comercial. Já, para a zeólita Beta, a atividade foi maior, apresentando uma decomposição do corante acima dos $97 \%$, isto sendo um indicativo de que estruturas mais acessíveis (com poros maiores) auxiliam na dispersão do $\mathrm{TiO}_{2}$, fazendo com que este fique mais acessível e, assim,

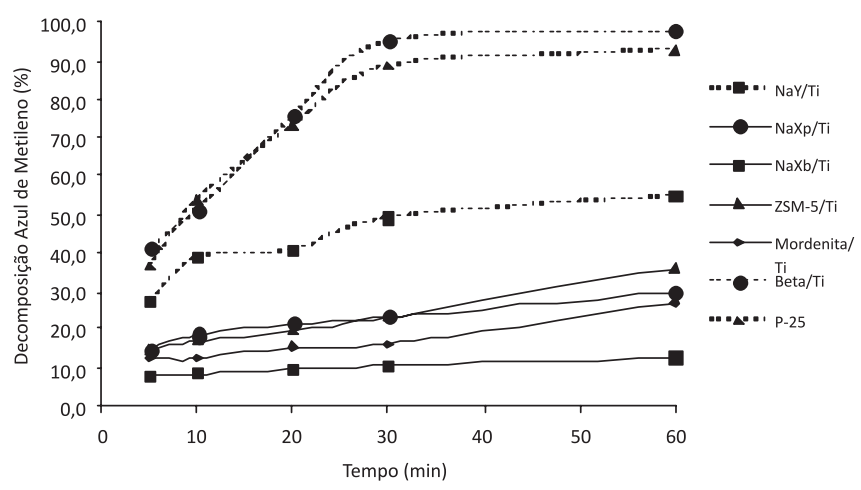

Figura 7. Monitoramento da decomposição do azul de metileno empregando os diferentes fotocatalisadores mais ativo. Desta maneira, esta estrutura mais acessível mostra ter grande importância, uma vez que o gap de energia apresentado pela amostra Beta/Ti, Tabela 2, sugere uma menor eficiência na fotodecomposição do azul de metileno.

\section{CONCLUSÕES}

Os resultados obtidos mostram que o processo de fotocatálise heterogênea pode ter seu desempenho aumentado, da ordem do fotocatalisador de titânia comercial. O método utilizado para incorporação de $\mathrm{TiO}_{2}$ em zeólitas mostrou-se eficiente, visto que foram obtidos catalisadores com alta atividade na fotodegradação e adsorção do corante sob irradiação de luz UV-vis. Com a principal vantagem, em comparação com a titânia comercial, de apresentarem grandes tamanhos de grãos o que, por sua vez, torna mais fácil sua separação e reutilização. O tamanho dos catalisadores suportados encontra-se na escala micrométrica, enquanto que o comercial está na escala namométrica. É importante ressalvar o efeito de adsorção que os suportes zeolíticos apresentam, contribuindo com a aproximação entre o contaminante e os sítios catalíticos localizados na superfície do suporte, proporcionando um elevado grau de fotodecomposição sob irradiação UV-vis, conforme apresentado pela amostra Beta/Ti.

Os resultados obtidos mostram que a aplicação do processo de fotocatálise heterogênea com zeólita e $\mathrm{TiO}_{2}$, na degradação de efluentes industriais, pode ser uma alternativa promissora para viabilizar, em um futuro próximo, a aplicação deste processo no tratamento de efluentes industriais que contenham poluentes recalcitrantes aos processos tradicionais, contribuindo assim para preservar ou melhorar a qualidade dos recursos hídricos.

\section{AGRADECIMENTOS}

À URI - Campus Erechim e ao Laboratório de Difração de raios-X - UFRGS pelas análises de DRX. Degussa é agradecida pela doação de P25.

\section{REFERÊNCIAS}

1. Nogueira, R. F. P.; Jardim, W. F.; Quim. Nova. 1998, 21, 69.

2. Gross, M.; Petrovic, M.; Barceló, D.; Hdb. Env. Chem. 2008, 5, Part S/1, 37.

3. Ferreira, I. V. L.; Daniel, L. A.; Eng. Sanit. Ambient. 2004, 9, 1413.

4. Herrmann, J. M.; Catal. Today 1999, 53, 115.

5. Chatti, R.; Rayalu, S. S.; Dubey, N.; Labhsetwar, N.; Devotta, S.; Sol. Energy Mat. Sol. Cells 2007, 91, 180.

6. Alvaro, M.; Carbonell, E.; García, H.; Appl. Catal. B 2004, 51, 195.

7. Panpa, W.; Sujaridworakun, P.; Jinawath, S.; Appl. Catal. B 2008, 80, 271.

8. Huang, M.; Xu, C.; Wu, Z.; Huang, Y.; Lin, J.; Wu, J.; Dyes Pigm. 2008, 77, 327.

9. Aprile, C.; Corma, A.; Garcia, H.; Phys. Chem. Chem. Phys. 2008, 10, 769.

10. Anandan, S.; Dyes Pigm. 2008, 76, 535.

11. Pergher, S. B. C.; Oliveira, L. C. A.; Smaniotto, A.; Petkowicz, D. I.; Quim. Nova 2005, 28, 751 .

12. Petkowicz, D. I.; Brambilla, R.; Radtke, C.; Rocha, Z.; Pergher, S. B. C.; Dos Santos, J. H. Z.; Appl. Catal. A 2009, 357, 125.

13. Nagy, J. B.; Bodart, P.; Hannus, I.; Kiricsi, I.; Synthesis, chacterization and use of zeolitic microporous materials, $1^{\text {st }}$ ed., Ed. DecaGen Ltd.: Hungria, 1998.

14. Liqianga, J.; Xiaojuna, S.; Weimina, C.; Zilic, X.; Yaoguoc, D.; Honggang, F.; J. Phys. Chem. Solids 2003, 64, 615. 